\title{
A Dialectical Dialogue about the Fairness of Intellectual Property Rights
}

\section{Rongqing Dai*}

Freelance Philosopher, New Jersey, USA

\begin{abstract}
Human ingenious creations are the basic bricks of the edifice of our civilization and correspondingly Intellectual Property Rights (IPR) became one integral part of modern civilization. Starting with the very basic nature of Intellectual Property (IP) in comparison to the nature of physical entities like cars, this writing explores the logic behind IPR related fairness by making use of Platonic style dialectic dialogue. Some key factors that would impact the fairness of IPR in a society are discussed.

This writing re-exhibits the power of the ancient technique of dialectic dialogue for explicating complicated social issues like IPR. Reference to some previous discussion on fairness in general by the author, together with some other relevant ancient philosophical thinking, is also provided in this writing.
\end{abstract}

Keywords: Intellectual Property; Right; Fairness; Philosophy; Law; Dialectic

\section{Introduction}

According to the definition given by the World Intellectual Property Organization [1], intellectual property (IP) refers to creations of the mind, such as inventions; literary and artistic works; designs; and symbols, names and images used in commerce, which is protected in law by, for example, patents, copyright and trademarks, which enable people to earn recognition or financial benefit from what they invent or create. By striking the right balance between the interests of innovators and the wider public interest, the IP system aims to foster an environment in which creativity and innovation can flourish.

Although IPR has been one integral part of human civilization for centuries, and was actually written into The Universal Declaration of Human Rights [2] (UDHR) and proclaimed by the United Nations General Assembly in Paris on 10 December 1948, it is still by no means an issue free of controversy [3,4]. As a matter of fact, a central implicit theme hidden in the arguments either of proponents or opponents of IPR is fairness. The main difficulty involved in this issue is the metaphysical complicacy of fairness [5], which is further complicated by human weakness in handling metaphysical concepts in general.

The sense of fairness is very relative. Whenever we discuss the fairness of a specific issue, if we attempt to get an absolute fair result, we might find that we are dragged into an endless loop of deconstructing what is fair and what is not fair. It is like to pull a thread of fiber out of a nylon stocking as an effort to get rid of it but then end up with getting more and more nylon fiber off the stocking. As an abstract concept, fairness is easy to understand but hard to define with a fixed denotation. This fundamental difficulty of handling fairness would inevitably be reflected in the affair of IPR.

When it comes to legal matters, people usually tend to ensure the fairness of any issue to be as general as possible while intentionally or inadvertently ignoring many particularities, for otherwise they might feel difficult to handle the challenge of unfairness and the correspondent possible injustice in general. But on the other hand, the particularities in many situations might ruin the sense of fairness that has been established for general cases. As we might find out later in this writing, the sense of fairness about IPR might not be universally invariable as it might be affected by some detailed factors. For a better understanding of the complicacy of fairness behind the affair of IPR, we need to clearly expound various aspects, which might be related to conflicted interests, in a logically consistent way from the very basics to the most complicated aspects. This type of task could be best accomplished by means of Platonic style dialectical dialogue as I would compose in this writing.

\section{About Dialectic Dialogue}

Dialectic dialogue (or dialectic method or simply dialectics) is a technique of writing in the form of discourse between multiple people holding different points of view about a subject but wishing to reach the truth through reasoning. It could be found from ancient literatures of different cultures but most famous for the dialogues written by the great Greek philosopher Plato. About dialectic Plato made such a comment in his famous dialogue, The Republic [6]: “... so with dialectic; when a person starts on the discovery of the absolute by the light of reason only, and without any assistance of sense, and perseveres until by pure intelligence he arrives at the perception of the absolute good, he at last finds himself at the end of the intellectual world, as in the case of sight at the end of the visible."

Plato usually managed to make his dialogues look like real happenings in the history by presenting a dialogue in the form of casual conversation and adding personal salutations and courtesies before and during the main discourse. But from the lengthy details of his dialogues and the fact that he was not at the scene when the events had happened, we could be assured that those dialogues could not be genuine records of real happenings even though they might be based upon some real stories.

Comparing to other forms of discourse, a dialectic dialogue could flexibly disintegrate narratives about different aspects (often in contradicting appearance) into smaller units with the help of exchanges between different characters in the dialogue, and thus help to elucidate complicated logical relationships so that it would be easier for ordinary *Corresponding author: Dai R, Ph. D, Freelance Philosopher, New Jersey, USA,
Tel: + 0017185147243; E-mail: ronald_dai@yahoo.com

Received November 20, 2016; Accepted December 24, 2016; Published December 31, 2016

Citation: Dai R (2016) A Dialectical Dialogue about the Fairness of Intellectual Property Rights. Intel Prop Rights. 5: 173. doi: 10.4172/2375-4516.1000173

Copyright: (c) 2016 Dai R. This is an open-access article distributed under the terms of the Creative Commons Attribution License, which permits unrestricted use, distribution, and reproduction in any medium, provided the original author and source are credited. 
readers to apprehend them. It could even go into very minute details that might not be easy for other forms of discourse to get into.

In the next section of this writing, I will construct a Platonic style virtual dialectic dialogue to explicate the complicacy of fairness behind IPR.

\section{The Dialectic Dialogue about IPR}

To pay homage to Plato and Socrates, let's suppose that we have two descendants from the characters of The Republic in our dialogue, the descendant of Socrates and the descendant of Glaucon, and I will name them as DS and DG. In order to help readers to grasp the dialectical logic behind the issue, I would further divide the dialogue into different subsections with italic titles. Now let's start our dialogue:

\section{The basics}

DG: Hi DS, I would like to have a chat with you about Intellectual Property Rights (i.e. IPR).

DS: You want to discuss how to make laws to protect IPR?

DG: Not really, because that might be too hard for you since you are not a legal expert.

DS: Thanks for being considerate of me. Then what do you want to discuss?

DG: As we know that although IPR has been one integral part of modern civilization for centuries, it is still a controversial issue. I feel that people might understand the issue better if they are better informed about the philosophy behind it.

DS: That I can help. First of all, let me ask, what do you think to be the most important philosophical issue for IPR?

DG: Fairness. Personally I think that fairness is the main theme behind the issue of IPR. IPR?

DS: I agree. Then what is the basic concern about the fairness of

DG: It is certainly that whoever toils to create an IP product [7] should have the right to enjoy the benefit of it and that is fair. It is exactly the same as that a car maker who toils to produce a car would have the right to enjoy the benefit of it.

DS: You are correct in principle but you just missed one key difference between Intellectual Property and cars. That would make the rights of IP creators (or we might call them as innovators) quite different from the rights of car makers.

\section{DG: What is that?}

DS: The difference between the conservation laws controlling the entities of IP and cars.

\section{DG: What do you mean?}

DS: As physical entities, cars are under the control of the law of conservation of mass, which means nobody can make use of a car unless he physically takes it away; but Intellectual Property products are fundamentally various forms of information which follow the law of conservation of information that is different from the law of conservation of mass, and thus any IP product could be shared with multitude without losing the original sample, which means anyone could take the advantage of any piece of Intellectual Property as long as he has learned or copied the content of it.

\section{DG: You are awfully right about that.}

DS: For this reason, if someone bought a car from a car maker, he could either makes use of it by himself or sell it to someone else. $\mathrm{He}$ could not both own it and sell it to profit; but if someone bought an IP product, he might be able to sell unlimited copies of it to profit while he still make use of it by himself if it is allowed. That's the basic difference.

This difference determines that for cars that follow the law of conservation of mass we need to protect the ownership of cars that are entities of mass, but for various forms of Intellectual Property that are basically various forms of information and thus follow the law of conservation of information we need to protect the ownership of the information itself.

\section{DG: That sounds reasonable.}

DS: However, this would cause all the controversies about IPR.

DG: Why?

DS: The ownership of one car does not entail the ownership of all cars. But the ownership of one form of IP means nobody is allowed to reproduce it at all without the permission of the owner. It would be a monopoly over that specific form of IP.

DG: The word monopoly sounds troublesome.

DS: But we have to live with it since it is determined by the fundamental nature of information.

\section{DG: I guess so.}

DS: There are two different layers of protection of IPR, or we might say two different senses of protection. The basic layer is the moral layer, and the second layer is the financial layer. Both of them could be enhanced by various legal means.

\section{DG: What is the moral layer protection?}

DS: At the moral layer, at least, anyone who makes use of an IP product that was produced by someone else should not claim the credit for the originality of the production; when it is necessary he should explicitly give the credit to the original contributor when using it. Since not all IP products could be tagged with a price and sold for cash, the moral protection by the society is more basic than the protection of financial interests of the IP creators. For example, no one should be allowed to take another person's article and change the author's name to his own name and publish it.

DG: Of course. This moral layer should be the foundation of any IPR issue since as you just mentioned IP products could be reproduced unlimitedly without much effort.

DS: Yes. Accordingly, the moral layer protection might not be controversial among the public. What could cause controversies is the financial layer protection.

DG: I am a bit confused about that. Based on what you just said about the different natures of making use of cars and making use of IP products, we should just simply forbid anyone from using an IP product without the permission of the creator of the product. When they ask for the permission of the creator, the creator could charge money for the product just like the car makers charge the buyers for the cars. Why would that be controversial?

\section{Fairness versus unfairness}

DS: The basic source of controversy is the monopoly nature of IPR. 
Because of the monopoly nature of IPR, there are two reasons that might make what you just suggested not as fair as it would appear to be.

\section{DG: What are they?}

DS: First of all, because of its monopoly nature the claim of IPR becomes a competition. Suppose that two people are working at the same time for the same invention, but one of them was a little faster than the other to apply for the patent, or he is more familiar with the procedure of applying for a patent than the other, and he is awarded the patent. Once he is awarded that patent as the IPR, theoretically speaking the other person would be asked to pay for using something he invented by himself independently just because someone else applied for a patent faster, would that be considered fair?

DG: No. But the chance for that to happen should be minimal, right? Besides, if someone could prove that he was doing the same independently, then he might be allowed to make use of it by the law.

DS: First of all, theoretically, even for something with the minimal chance we cannot guarantee that it would not happen; and when it happens if the person is required to pay for what he invented independently, it is not fair in principle, right?

Secondly, in real life, even if the law would offer some exception to someone who could prove that he invented a patented IP product by himself, there could be a lot of troubles for anyone to prove it. As a matter of fact, the legal system would intentionally make it very difficult to prove since otherwise they might need to worry about the chance that everyone could fake it.

DG: But if the chance is minimal we might still not worry too much about it in real life.

DS: Well, first of all, people might argue that principles should not be intentionally compromised in any case. Secondly, the impact of the rights of monopoly through IPR might not always be minimal. It actually might impact the general fairness of the society.

\section{DG: How could that be?}

DS: As an example, once an inventor is granted with a patent which is the right of monopoly in nature, it is not only entailing some possible trouble for those who were working on the same thing at the same time, but also effectively blocking any future efforts of creating the same independently by others as long as the patent stays valid.

While we all agree that it is fair for the IP creator to enjoy the blessing from his own hard working, it is not essentially fair for the rights of others to do the same to be deprived in the future simply because someone else did it in the past.

DG: But what else can we do considering the different natures between IP products and physical products as you elaborated earlier?

DS: That we don't know yet. Let's first work out the philosophy clearly without worrying much about how to deal with the issue practically.

DG: I agree. You mentioned that there are two reasons that might make the monopoly type of protection of IPR not be fundamentally fair. Now you have only given one even though it might sound like two. What is the other one?

DS: You are right and I have not talked about the other one yet. The second reason is the fairness between the IP creator and the society in general.
We might all agree that no matter how much effort a person or an organization have spent on an IP creation, without the support and generosity of the society in various forms, they could not have achieved what they have now.

DG: Certainly. Cavemen could not create nowadays IP products. Or at least, neither individual persons nor companies could survive without the support of the society.

DS: But a right of monopoly on an IP product would undoubtedly impede the general public from making a full use of that IP freely, which is not fair in the sense that the creation of the IP was partly supported by the society. This might become especially important for some IP products that could be beneficial in life saving or disaster battling.

DG: You are making some sense. However, we might also look at this from another angle that we are all supported by the same society in the sense that we are all living in the same society, but someone created the IP and others did not. Shouldn't they be treated differently?

DS: Of course they should. This brings us back to the basics we mentioned earlier that IP creators should have the rights to benefit from their efforts to create the IP products.

Now we have seen three basic factors that contribute to the logical difficulty for IPR protection:

1) As we have repeatedly said, the IP creators should have the rights to benefit from their creation;

2) Since IP is not under the control of the law of conservation of mass, we need to let IP creators to have the monopoly on their products in order to protect their rights;

3) The monopoly of IP creators might cause unfairness to others or to the whole society for those two reasons that we just talked about.

Therefore, what we are facing is actually the logical conflict between different ideal fairness judgments from different angles of view, which is a manifestation of the fundamental weakness of human beings for handling ideal concepts like fairness.

DG: Well, isn't any Right of Intellectual Property normally time limited? That could solve the problem, right?

DS: That could only alleviate the conflict but might not solve the problem completely. If the time is too short then it might not help the innovators very much, but if the time is too long then it might not be fair for others in some cases. For example, if a patent is valid for 30 years, then many other people could not fully enjoy the benefit of something that they might have been able to invent independently in much less time if it is not blocked by the patent.

DG: Then what can we do?

DS: We might not have a universally valid perfect solution at this stage yet.

DG: Aren't you too much pessimistic?

DS: I just don't want to rush into some simple answer. Besides, not all Intellectual Property Rights are the same in terms of complicacy of fairness. There are three common forms of IPR that most people are familiar with, which are trademark, copyright, and patent. The sense of fairness about the right of monopoly is quite different for each of these three.

The simplest case might be with trademarks. The proper protection 
of trademark would cause almost no negative impact on the society in general (except for some possible inconvenience to relevant parties) no matter how long the right would last, considering the richness of graphical patterns and vocabulary in any natural language.

The possible negative impact upon the society from copyright protection would also be quite limited. Let's take the copyrights of writings of an example. There are two different types of writings. The first type of writings is mainly for entertainment and the second type of writings is those from which people would learn knowledge or skills including the skill to think. For those that are for entertainment, without them the society might lose some fun but it can always be made up from some other ways; and thus it would not cause any damage to the society if we allow the authors to own the monopoly (i.e. the copyrights) over their writings for a very long time. For those from which people would learn knowledge, as long as they could obtain the writings from the market at reasonable prices, it is also okay for the authors to own the copyrights for a long time since it would not cause serious damage to the society by doing this either.

The fundamental reason that long term monopoly of trademarks and copyrights would not hurt the society much is that those rights only protect the financial interests of the owners but do not block others to create similar products as long as they don't attempt to steal the content or credit of the original authors.

On the contrary, a patent of a technology might be used to block others to create the similar ones for a while in the future. This is because patent deals with ideas. Ideas could inspire the creation of similar ones. If patent only protects some exact designs with very specific details as trademark or copyright does, then it would be very easy to breach patented rights with different but similar designs.

\section{Incentive concerns}

DG: That is true. However, I don't hear you mention the incentive for creation. Isn't that also part of the fairness behind the IPR?

DS: Good question. You just bring our conversation up to a higher order of consideration about the fairness issue behind the IPR.

\section{DG: Why do you say so?}

DS: So far we have examined the fairness issue solely based on the consideration of the balance between the work to create and the benefit from the creation. As you noticed that we have not mentioned incentives yet, which we should certainly not miss in our discussion.

Incentives are closely connected to fairness in many ways, but incentives are also different from fairness in the sense that people do not always act for the fairness of everyone although they would feel uncomfortable or mad if they could not be treated fairly by others or even by themselves.

\section{DG: I agree.}

DS: One important reason to protect IPR is to encourage people to create productively. In this sense, the IPR is one type of reward for creation for the society so that it could be counted as a good incentive for people to create or to invest for creation.

DG: Would you count the altruistic passion to benefit the society as one of the incentives?

DS: No, not here. That would be a great virtue but not part of our consideration here. When we discuss the IPR related fairness, we would only consider personal interest related benefit so that we would not lose our focus.

\section{DG: Fair enough.}

DS: Incentives for creation are related to different social needs. So we might better understand different incentives here by looking into what kind of needs that IPR might be used to serve.

\section{DG: Good idea.}

DS: When we talk about creation, there are two basic elements involved. The first is the work to create, and the second is the resources for any creation to be carried out and for the social realization of the value of the creation.

The ingenious work of human beings is the most essential element of any creation. People create not only to bring various conveniences to the world but also to meet various needs for themselves. The most important need among all others would be the need for personal survival and growth in the society. Many individuals make a living by creating independently or doing creative work for their employers. For those independent innovators (e.g. independent writers and artists and inventors), the benefit protected with IPR, no matter as copyright or patent or in any other forms, might be the only source of living. If they could not earn income from that source due to the infringement of rights, they might not be able to survive. Or even if they could manage to maintain terrible living conditions, they might no longer be able to create efficiently for the society. That would be not only unfair to them personally but also tremendous waste of talent and waste of valuable resources to the society in general.

The value of any creation would be realized only after it is recognized by others in the society. However, in many cases (e.g. independent writers and inventors) those individual innovators might not be able to bring their IP products to the public, especially when they have not become famous yet. This would establish the logical need for commercial entities (e.g. traditional publishers and agents or enterprises that need new inventions) that would help to market and sell those IP products or put them into practical uses. For the same reason why IP creators need to be awarded monopoly type of rights (i.e. the reason that IP products could be reproduced easily), these commercial entities also need to have monopoly type of rights to protect their interests after they invest capital and other resources to make those IP products worthy to the world. Therefore, as an exchange, these entities might ask for the share or transfer of IPR from the original creators.

Very often creations, especially most advanced high tech inventions, could be carried out only with expensive equipment and the cooperation of a team of players supported by large amounts of capital. It is a common nowadays phenomenon that large corporations are leading the high tech inventions of the world. After investing large amounts of capital for new inventions those companies would also expect that their investment could be protected by monopoly rights.

Although there are many other types of needs for IPR, the above three types would provide a good set of samples for us to get a sense of the challenge of balancing those three factors that we mentioned previously for the fairness of IPR.

\section{Further analysis}

DG: It would be interesting to hear your discussion about the challenge.

DS: Actually, the critical concern that matters in the consideration 
of balancing those three factors (i.e. the fair benefits of innovators, the possible negative social impact of hampering the society from enjoying the creations or even blocking others to create the same, and the incentive to make new creations) is how to measure those three factors, which would cause the transition from the quantitative change to qualitative change as Hegel discussed [8]. If we solely look at those three factors conceptually which are in conflict with each other in some ways we won't be able to get to anywhere in the debate between the proponents and opponents of IPR since each side could make a legitimate argument on their own behalf. But if we further look into each of the factors and sense the subtlety in the related measure we could see the issue in a more reasonable way.

For example, sometimes opponents of IPR could go to the extreme of against any form of IPR protection by emphasizing that it is not fair for anyone to make their own financial benefit at the cost of impeding the public to share their knowledge freely. When doing so they obviously forget the fact that there is a huge difference between, for example, someone who makes a living by writing or inventing new technology diligently and some big corporation that produces billions of dollars of extra dividend for their directors of board annually by taking advantage of the monopoly of IPR. As I mentioned earlier without the fair payback for their creations many individuals might hardly survive or decently develop in the society.

DG: As I can see, a simple answer to this dilemma is to only protect IPR for individuals, not for big corporations.

DS: Then you might ruin the incentive to invest in new technology that is critical for the development of our civilization in this high tech era.

DG: Then let's just manage to let those who invest their money to get not too much more and not too much less than their fair payback.

DS: Well, that is a task with some fundamental difficulty due to the intrinsic human weakness of handling measure.

DG: Why do you say so?

DS: Are you familiar with the Sorites Paradox?

DG: What is it?

DS: The word sorites derives from the Greek word soros which means 'heap' [9]. The paradox goes like this:

There is a heap of sand with millions of sand grains. You start to remove sand grains one by one from the heap and finally that heap will disappear. But at any specific step you just remove one sand grain, and any one sand grain cannot make difference between a heap and not a heap.

DG: Wow, it is indeed a paradoxical situation.

DS: People might get different morals from this paradox, but to me the most profound meaning from this paradox is human impotence of perceiving the gradual variations. The same would happen when people attempt to define what is too much more and what is too much less.

DG: It seems that after such a lengthy discussion we might be let down by a genetic weakness in human nature. Does that mean we won't be able to find any universally valid and definite solution to our original problem, the controversy about IPR?

DS: After all, we know the issue better philosophically, don't we?

DG: I would say so, but...
DS: Don't feel too sorry for that we cannot reach a universally valid solution for the issue.

We need to have a better understanding about the issue before we might further take any action for the good of the society. For example, it is a global mantra that everyone is equal before the law. Thus when it comes to legislation for IPR, it would be natural for law makers to propose that any relevant law should be fair to everyone without looking into his personal background. However, based on our conversation we know that it is the very detailed differences between personal or corporate conditions that would determine whether the payback is reasonably fair for the innovators and investors or exaggeratedly overcharged at the cost of public interest.

DG: Would you consider it necessary that people take detailed personal or corporate background into consideration for IPR related legislation?

DS: I don't have a simple answer for that. Again we are facing the fundamental human weakness in dealing with measure for gradually varying matters. In many cases it would be much easier to assume the conceptual fairness to everyone without looking into the individual background. Even if people attempt to improve the fairness by looking into the huge variety of individual situations, it might be a very big challenge due to many complicated factors including the cost of doing so.

DG: Then what are we supposed to do?

DS: Philosophy could help us to better understand the logic, but social changes would often involve some tough political maneuvers which might be different for different cultural environments. So we might just let philosophers work on philosophy and let politicians to handle politics.

DG: That makes sense. I guess we might end our conversation here. Thanks for the discussion and I really enjoy it.

DS: I enjoy it very much as well. Thanks.

\section{Conclusion}

Human ingenious creations are the basic bricks of the edifice of our civilization. But human creators are biological and social beings with various needs for survival and growth in this world; therefore, the protection of their rights to enjoy the benefit of creation becomes a meaningful logical element of our modern life. To most people Intellectual Property Rights might not sound as important as many other pressing social challenges, or even not a familiar terminology, which nonetheless would not make it an easy issue to handle. This is because of the complicacy of fairness involved in the issue. This writing has ventured to lay out the basic logic behind the issue of IPR in terms of fairness by using the classic dialectic method.

One of the basic tasks of philosophy is the removal of social confusions at various times around the world. Dialectic dialogue is actually very effective for this task because it is very convenient to let characters in the dialogue to speak out whatever might be causing confusion among the public. But like many other forms of philosophical writing, the biggest challenge is still the rigorous logic and the clarity of discourse of the subject, which is what I have been endeavoring to achieve for this article. Hopefully it could provide an example of how to use this once popular ancient technique in modern times for various challenges in our life.

As a philosophical discourse, this writing is obviously not meant to provide a definite solution for how we should deal with legislative issues 
Citation: Dai R (2017) A Dialectical Dialogue about the Fairness of Intellectual Property Rights. Intel Prop Rights. 5: 173. doi: 10.4172/23754516.1000173

Page 6 of 6

of IPR; rather, it is only meant to help the public to better understand the logic behind the fairness of IPR.

\section{References}

1. What is Intellectual Property? World Intellectual Property Organization.

2. Assembly UG (1948) Universal declaration of human rights. UN General Assembly.

3. Petra M (2013) Patents and Innovation: Evidence from Economic History, Journal of Economic Perspectives 27: 23-44.

4. Joshua M. Pearce, (2012) Nature, Make Nanotechnology Research OpenSource 491: 519 .
5. Dai R (2016) A Short Introduction to the Paradoxical and Dynamic Nature of Fairness, by J. Civil \& Legal Sciences.

6. The Republic, by Plato, trans. Allan Bloom, Basic Books.

7. Barker S (2014) IP Language Curmudgeon Archives, Serving the Global Intellectual Property Community. Intellectual Property Owners Association 1501 M St. NW.

8. Hegel G (1816) The Objective Logic Book One (Vol 1): The Doctrine of BeingHegel's Science of Logic.

9. Sorites Paradox, Stanford Encyclopedia of Philosophy. 